\title{
Transnasal sphenopalatine ganglion block for the treatment of postdural puncture headache after caesarean section
}

\author{
Bilge Aslan \\ Zekai Tahir Burak Training and Research Hospital, Department of Anesthesiology and Reanimation, Ankara, Turkey
}

Keywords: Sphenopalatine ganglion block, postdural puncture headache

Background: The sphenopalatine ganglion (SPG) is a parasympathetic ganglion, located in the pterygopalatine fossa. The SPG block has been using for a long time in the treatment of headache of various reasons. Treating postdural puncture headaches (PDPH) has always been challenging. Epidural block patch (EBP) can be still considered if an SPG block is not able to alleviate pain due to PDPH.

Method: Tweenty female patients with mean age 26.7 55.5 (1937) were included in this study. All patients underwent cesarean section under spinal anesthesia with using $26 \mathrm{G}$ spinal needle. Patients were ASA I or II. Mean reconsultation time due to headache was $65.2 \pm 9.3$ (47-80) hour. Patients with Visuel Analog Scale $(\mathrm{VAS}) \geq 4$ were treated.

Technique; The Cotton-tipped applicators, one for each nostril, were inserted parallel to the nose floor and advanced until resistance was felt. This represents contact with the posterior nasopharynx wall (Figure 1). The patient needs to be in a supine position with the neck extended. The cotton-tipped applicator was soaked up with $0.3 \mathrm{ml}$ of $0.5 \%$ bupivacaine and was held for 5 minutes. At the fifth minute $0.2 \mathrm{ml}$ of bupivacaine was sent through the lumen and the cotton was held for additional 5 minutes. Then applicator was removed. VAS score, blood pressure and oxygen saturation were taken immediately and followed for 24 hours. Repeated measures of analysis of variance was used.

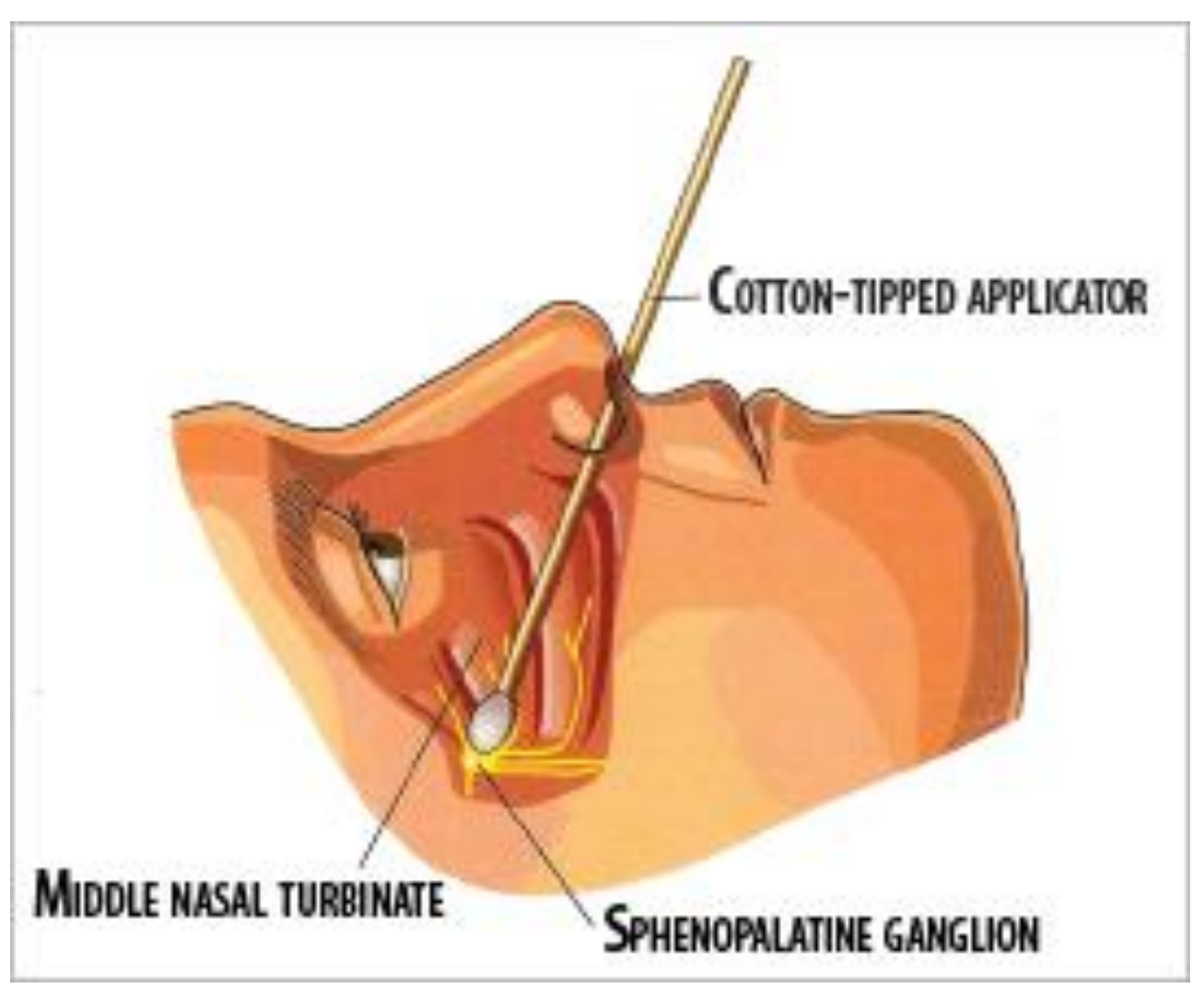

Figure 1. Technique of SPG block.
Results: Headache improved rapidly in all patients immediately after administration and there was a significant improvement in VAS scores $(\mathrm{p}<0.001)$. However, headache again revealed at 6 th hour in 5 patients. SPG block was reapplied for his patients (Figure 2). Side effect and complication were not observed. Patients were discharged 24 hours after being observed and then prescribed caffeine 520 mg-acetaminophen $4000 \mathrm{mg}$ orally in 24 hours.

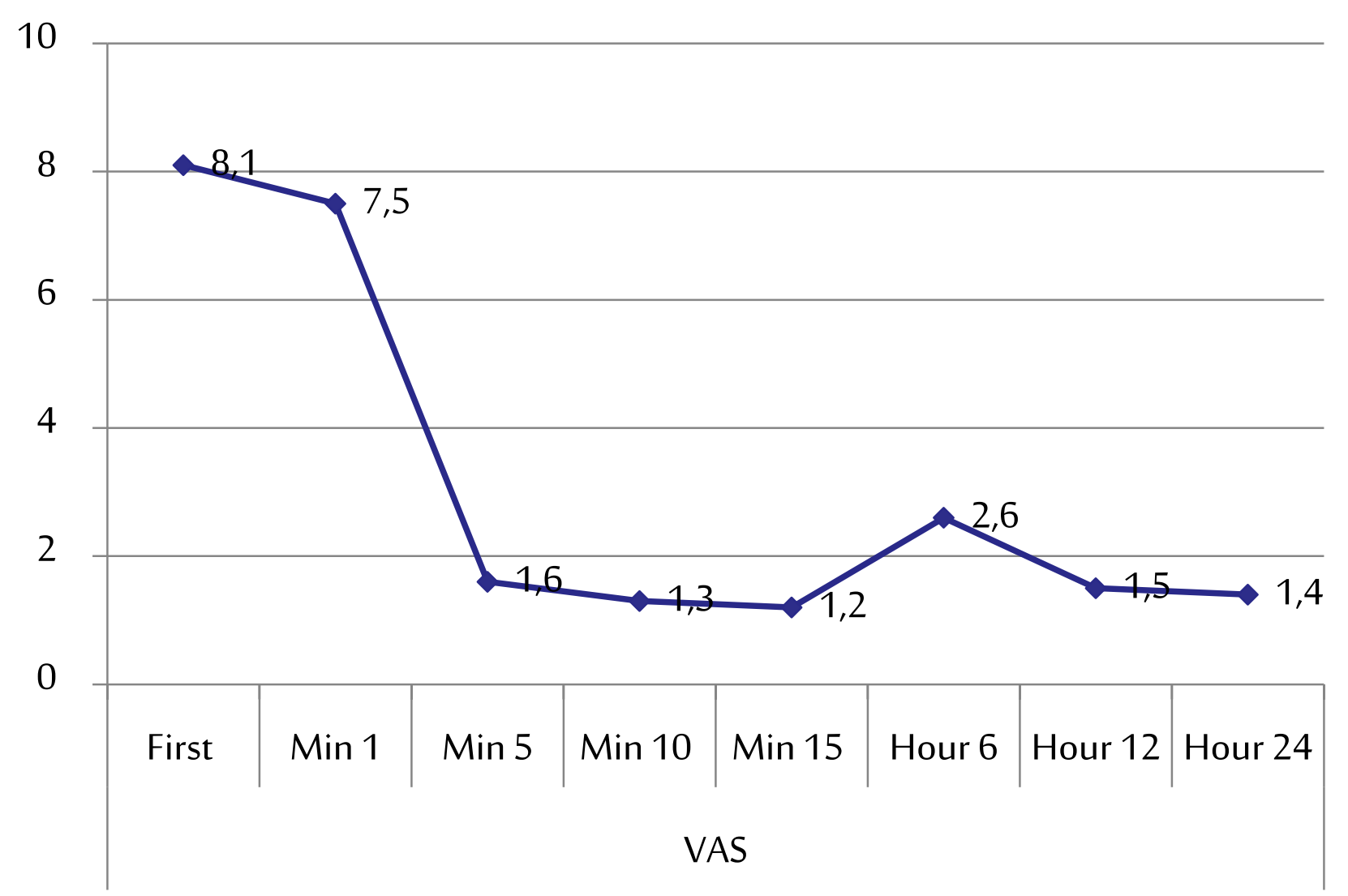

Figure 2. VAS values of patients after application.

Conclusion: SPG blockade is an easy, quick, safe and effective procedure for PDPH. We believe that large prospective studies are needed to confirm our results.

\section{References:}

1. Turnbull DK, Shepherd DB. Post-dural puncture headache: Pathogenesis, prevention and treatment. $\mathrm{Br} \mathrm{J}$ Anaesth 2003;91:718-29.

2. Nair AS, Rayani BK. Sphenopalatine ganglion block for relieving postdural puncture headache: technique and mechanism of action of block with a narrative review of efficacy. Korean J Pain 2017; 30(2):93-97.

3. Kent S, Mehaffey G. Transnasal sphenopalatine ganglion block for the treatment of postdural puncture headache in obstetric patients. J Clin Anesth 2016;34:194.6. 